\title{
RESISTÊNCIA DE PLANTAS DANINHAS AOS HERBICIDAS ${ }^{1}$
}

\author{
PEDRO J. CHRISTOFFOLETI ${ }^{2}$, RICARDO VICTORIA FILHO ${ }^{\mathrm{S}}$ e CLÓVIS B. DA SILVA
}

\begin{abstract}
RESUMO
A resistência de plantas daninhas aos herbicidas ocorre em função de um processo evolutivo. O desenvolvimento de biótipos de plantas daninhas resistentes é imposto pela agricultura moderna, através da pressão de seleção causada pelo uso intensivo dos herbicidas. O conhecimento dos mecanismos e fatores que favorecem o aparecimento de bió-

técnicas de manejo sejam utilizadas no sentido de evitar ou retardar o aparecimento de plantas resistentes em uma área. São poucos os relatos ou citações de literatura no Brasil. Sendo assim, este trabalho de revisão procura relatar os principais avanços e descobertas na área de plantas daninhas resistentes aos herbicidas.
\end{abstract} tipos de plantas daninhas resistentes é fundamental para que
Palavras-chave: desenvolvimento de resistência.

\section{ABSTRACT \\ Weed resistance to herbicides}

Weed herbicide resistance has evolved from weed evolution. The modern agriculture is responsible for this evolution because of the intensive use of herbicides. The knowledge of mechanisms and factors that influence the weed herbicide resistance play an important role in the weed manegement techniques used to avoid or delay herbicide

\section{INTRODUÇÃO}

As plantas daninhas surgiram de um processo dinâmico de evolução ao adaptarem-se às perturbações ambientais provocadas pela natureza ou pelo homem através da agricultura. Esta evolução continua até hoje em resposta à modernização da agricultura. Dentre as modernas técnicas usadas na agricultura, os herbicidas aplicados no controle das plantas daninhas têm proporcionado uma evolução bastante rápida das mesmas, tornando-as, em algumas situações, resistentes a estes produtos químicos. A evolução da população de plantas daninhas resistentes aos herbicidas é um problema crescente em muitos países. Sendo assim, muitos trabalhos de pesquisa têm sido conduzidos, especialmente nos últimos dez anos, procurando estudar distribuição, mecanismos de

1 Recebido para publicação em 29/10/93 e na forma revisada em 01/12/93

2 Prof. Doutor, Dept ${ }^{\circ}$ Horticultura, ESALQ-USP, Piracicaba, SP

3 Prof. Titular, Dept ${ }^{\circ}$ Horticultura, ESALQ-USP, Piracicaba, SP

4 Académico e Estagiário Dept ${ }^{\circ}$ Horticultura, ESALQ-USP, Piracicaba, SP resistance appearence. There are not many report or scientific papers about herbicide resistance in Brasil. Therefore, this literature review aims to provide information about the main advances and discoveries in the field of weed herbicide resistance.

Additional index words: resistance development.

resistência, genética e manejo dessas populações. Desta forma, o objetivo deste trabalho é de fornecer uma revisão concisa de alguns dos mais importantes avanços e descobertas recentes, relacionados com a evolução de biótipos de plantas daninhas resistentes aos herbicidas.

\section{RESISTÊNCIA DE PLANTAS DANINHAS AOS HERBICIDAS}

\section{DEFINIÇÕES}

Existe muita confusão na literatura sobre resistência de plantas daninhas aos herbicidas, quanto ao uso dos termos "resistência" e "tolerância". Erroneamente às vezes estes termos são usados indistintamente por algumas pessoas. Para este trabalho de revisão é importante definir-se claramente o termo resistência. Definições foram revisadas por Holt e LeBaron (1990). Para estes pesqui sadores qualquer definição do termo resistência de plantas daninhas aos herbicidas

Planta Daninha, v. 12, n. 1, 1994. 
deve sempre estar relacionada com a dose recomendada nas condições de campo para o controle das plantas daninhas.

Sawicki (1987) propôs uma definição que incorpora não apenas doses recomendadas, mas também o conceito de evolução. Sendo assim, resistência marca uma mudança genética nas plantas daninhas em resposta à seleção imposta pelos herbicidas usados normalmente em dosagens recomendadas. Rubim (1991) considerou que o termo resistência cruzada deveria ser empregado em casos em que uma população de plantas daninhas é resistente a dois ou mais herbicidas devido à presença de um único mecanismo de resistência. Em contraste, a resistência múltipla deveria ser usada nos casos em que a mesma planta resistente possui dois ou mais mecanismos de resistência distintos.

\section{INCIDÊNCIA}

O número de casos de resistência aos inseticidas e fungicidas aumentou rapidamente após as décadas de 50 e 60 , respectivamente. No final dos anos 80 havia mais de 500 espécies de insetos e acima de 150 patógenos que desenvolveram resistência aos inseticidas e fungicidas (Holt e LeBaron, 1990). No entanto, o aparecimento de plantas daninhas resistentes aos herbicidas é recente, apesar de os herbicidas seletivos serem usados há mais de 40 anos. Houve relativamente poucos relatos de resistência de plantas daninhas aos herbicidas ante riormente aos anos 60. Contudo, desde o primeiro relato feito por Ryan (1970), que observou biótipos resistentes de Senecio vulgaris aos herbicidas pertencentes ao grupo químico das triazinas, tem se observado um número crescente de espécies de plantas daninhas com biótipos resistentes não somente às triazinas, mas também a outras classes de herbicidas.

LeBaron (1991 e 1992) relatou que, por volta do ano de 1990, 113 biótipos de plantas daninhas resistentes aos herbicidas foram registrados por pesquisadores em várias regiões do mundo. Esse total inclui 58 espécies (41 dicotiledôneas e 17 gramíneas) de plantas daninhas resistentes às triazinas, e 55 espécies (36 dicotiledôneas e 19 gramíneas) resistentes a 14 outras classes de herbicidas (Tabela 1).

Na Europa, biótipos de 36 espécies de plantas daninhas desenvolveram resistência às triazinas (Van Oorschot 1991). Sete destas espécies foram encontradas no Reino Unido: Chenopodium album, Epilobium ciliatum, Erigeron canadensis, Matricaria matricarioides, Poa annua, Senecio vulgaris e Solanum nigrum (Clay, 1989). Resistência a paraquat foi detectada emEpilobium ciliatum e Poa annua (Clay, 1989) e resistência a mecoprop em Stellaria media (Lutman \& Heath, 1990).

Plantas daninhas resistentes aos herbicidas têm sido relatadas na maioria das regiões dos EUA, bem como em diversas províncias do Canadá, 18 países europeus e 11 outros países. Biótipos resistentes às triazinas são mais comumente encontrados nas seguintes espécies de plantas daninhas: Amaranthus hybridus, Amaranthus retroflexus, Kochia scoparia, Chenopodium album, Senecio vulgaris, Solanum nigrum e Poa annua.

A extensão da área afetada por plantas daninhas resistentes aos herbicidas é pobremente documentada devido à falta de relatos e pesquisas na área. No Brasil, por exemplo,
TABELA 1 - Ocorrência mundial de biótipos de plantas daninhas resistentes a diversas classes de herbicidas usados (extraídas de LeBaron (1991 e 1992)),

\begin{tabular}{|c|c|c|c|}
\hline $\begin{array}{l}\text { Classes de } \\
\text { herbicidas }\end{array}$ & $\begin{array}{l}\text { Exemplos de } \\
\text { herbicidas }\end{array}$ & $\begin{array}{c}\text { Número } \\
\text { de biótipos }\end{array}$ & $\begin{array}{l}\text { Número } \\
\text { de países }\end{array}$ \\
\hline Triazinas & Atrazina & 58 & 22 \\
\hline Bipiridilos & Paraquat & 16 & 9 \\
\hline $\begin{array}{l}\text { Inibidores da } \\
\text { ALS * }\end{array}$ & Clorosulfuron & 8 & 4 \\
\hline Fenil-uréias & Clorotoluron & 6 & 3 \\
\hline $\begin{array}{l}\text { Ácidos } \\
\text { Fenoxiacéticos }\end{array}$ & $\begin{array}{l}\text { MCPA, } \\
\text { mecoprop }\end{array}$ & 6 & 5 \\
\hline $\begin{array}{l}\text { Inibidores da } \\
\text { ACCase }^{* *}\end{array}$ & Diclofop metil & 4 & 5 \\
\hline Dinitroanilinas & Trifluralin & 3 & 2 \\
\hline Amidas & Propanil & 2 & 2 \\
\hline Triazoles & Aminotriazoles & 2 & 2 \\
\hline Uracilas & Bromacil & 2 & 1 \\
\hline Carbamatos & Femedifan & 2 & 1 \\
\hline Piridazinas & Cloridazon & 1 & 3 \\
\hline Nitrilas & Bromoxinil & 1 & 1 \\
\hline Organoarsenicais & MSMA & 1 & 1 \\
\hline \multirow[t]{2}{*}{ Ac. picolínico } & Picloran & 1 & 1 \\
\hline & TOTAL & 113 & \\
\hline
\end{tabular}

- ALS = acetolactate sintase

** ACCase = acetil coenzima A carboxilase

não existe nenhum trabalho de pesquisa ou relato, até o presente momento, sobre a incidência de biótipos de plantas daninhas resistentes aos herbicidas. Apesar disso, tem sido estimado que as plantas daninhas resistentes às triazinas infe stam cerca de 1 milhão de hectares nos EUA e pelo menos 2 milhões de hectares em outros países (LeBaron, 1991). Estas estimativas mostram a importância que deve ser dada ao assunto.

\section{DESENVOLVIMENTO}

$\mathrm{Na}$ maioria das vezes o surgimento de biótipos de plantas daninhas resistentes a certos herbicidas tem ocorrido em áreas onde é prática comum o uso repetido e subseqüente dos mesmos herbicidas ou diferentes herbicidas, mas com o mesmo mecanismo de ação. Este tipo de situação ocorre geralmente em sistemas intensivos de monocultivo, onde os herbicidas são aplicados com o objetivo de eliminar quase toda a população de plantas daninhas incidentes. Até o momento, a incidência de plantas daninhas resistentes tem ocorrido mais comumente nas áreas onde é praticado monocultivo de milho e trigo, bem como em áreas de horticultura, tais como pomares, viveiros, etc. Existem diversos relatos de resistência de plantas daninhas aos herbicidas em áreas não 
agrícolas tais como estradas-de-ferro, leitos-de-estradas e outras áreas, onde doses elevadas de herbicidas têm sido usada para "esterilização" do solo.

Não existe qualquer indicação de quais são as espécies, gêneros ou famílias botânicas de plantas daninhas mais adaptadas à evolução de resistência (LeBaron, 1991). No entanto, serão destacados alguns fatores geralmente considerados de fundamental importância no desenvolvimento de resistência de plantas daninhas aos herbicidas.

\section{FATORES QUE FAVORECEM O DESENVOLVIMENTO DE PLANTAS DANINHAS RESISTENTES}

\section{FREQÜÊNCIA INICIAL}

É provável que os biótipos de plantas daninhas resistentes estejam presentes nas populações de campo antes de qualquer exposição aos herbicidas, no entanto, em freqüências variáveis e bastante baixas. A freqüência inicial do genoma herdado com relação à resistência às triazinas em populações não selecionadas está entre $10^{110}$ e $10^{20}$ plantas por hectare (Gressel, 1991), enquanto que freqüência inicial mais alta, de $10^{-6}$ plantas por hectare, ocorre nos biótipos resistentes aos herbicidas inibidores da enzima ALS (Stannard \& Fay, 1987). Essas frequiências tendem a variar com a espécie de planta daninha, localidade e tipo de resistência, de modo que é muito difícil prever a frequiência inicial de um genótipo resistente em qualquer população de plantas daninhas.

Tais diferenças na freqüência inicial podem responder pelo desenvolvimento mais rápido da resistência ao herbicida clorosulfuron (inibidor da enzima ALS), haja vista que existem relatos de desenvolvimento de resistência depois de apenas 3-5 anos consecutivos de uso deste herbicida (Thill et al., 1991). No entanto, para as triazinas, o aparecimento de resistência ocorreu depois de 6-10 anos de uso consecutivo (Bandeen et al., 1982). Embora a frequiência inicial de plantas daninhas resistentes seja fundamental no desenvolvimento de resistência, sua determinação é muito difícil, pois ela é influenciada por muitos fatores, tais como pressão de seleção, características genéticas da resistência e dinâmica populacional das plantas daninhas.

\section{PRESSÃO DE SELEÇÃO}

Refere-se à proporção relativa de indivíduos resistentes e susceptíveis existentes antes e após o tratamento com herbicida (Gressel \& Segel, 1990; Gressel, 1991). Aplicações de herbicidas com efeito residual prolongado, como as triazinas, proporcionam uma alta pressão de seleção, pois as germinações sucessivas das diversas gerações de plantas daninhas ficam expostas ao herbicida e, conseqüentemente, a população de plantas daninhas sobreviventes adquirem uma proporção cada vez mais alta de indivíduos resistentes. $\mathrm{O}$ uso de herbicidas de ação foliar sem atividade residual, como o paraquat, também impõe uma alta pressão de seleção se as aplicações forem feitas repetidamente sempre que as plantas daninhas emergirem.
Dentre os fatores que tendem a influenciar a pressão de seleção podemos incluir intensidade de uso, eficiência e persistência do herbicida, eficácia dos mecanismos de resistência, especificidade do herbicida com relação ao seu modo de ação, padrão de emergência da planta daninha e eficiência dos métodos de controle não-químicos (Rubim, 1991).

\section{ADAPTAÇÃO ECOLÓGICA}

É definida geralmente como o sucesso reprodutivo ou a proporção de genes que um indivíduo deixa no conjunto de genes da população. Os dois componentes fundamentais da adaptação ecológica são: sobrevivência e reprodução (Silvertown, 1987). Experimentos que procuram comparar o sucesso reprodutivo e sobrevivência entre biótipos de plantas de uma mesma espécie, em condições de campo, são muito difíceis. Conseqüentemente, muitos estudos realizados com biótipos de plantas daninhas resistentes, em comparação com biótipos suscetíveis da mesma espécie, têm sido feitos medindo parâmetros, tais como taxa de crescimento e produção de biomassa. Estes parâmetros são usados como indicadores de diferenças de adaptação ecológica. Contudo, poucas inferências podem ser feitas sobre a adaptação ecológica de um biótipo resistente comparada com a de um susceptível, a partir de estudos de crescimento e biomassa em condições de campo, pois estes estudos são normalmente feitos em ambientes controlados (Holt, 1990).

Plantas daninhas resistentes às triazinas geralmente mostram pouco vigor vegetativo em comparação com biótipos susceptíveis das mesmas espécies (Holt, 1990). A atividade fotossintética menos eficiente, resultante de alterações nos sítios de ação dos herbicidas nas membranas dos cloroplastos, é considerada como sendo a razão do potencial fotossintético mais baixo e adaptação menor das plantas resistentes às tríazinas. Adaptações ecológicas e fisiológicas menores também têm sido relatadas com alguns outros tipos de resistência, como a resistência ao herbicida paraquat. No entanto, outros estudos têm mostrado que os parâmetros do potencial fotossintético do crescimento de algumas plantas daninhas resistentes às triazinas são similares àqueles encontrados em populações susceptíveis, isso em experimentos executados tanto em condições competitivas quanto em condições não-competitivas (Schonfeld et al., 1987). Além disso, não foram observadas evidências de taxa de crescimento inferior em Alopecurus myosuroides resistente a clorotoluron (Chauval \& Gasquez, 1991).

Existem evidências de que biótipos de plantas daninhas resistentes aos herbicidas inibidores da enzima ALS não são necessariamente menos produtivos que biótipos susceptíveis da mesma espécie. Christoffoleti (1992) desenvolveu pesquisa em condições de casa-de-vegetação e de campo, em que foi observado que não existe nenhuma diferença na adaptabilidade ecológica de biótipos resistentes e susceptíveis da planta daninha Kochia scoparia. Embora diversas pesquisas tenham sido desenvolvidas com o objetivo de determinar as diferenças de adaptação ecológica entre os biótipos resistentes e susceptíveis de plantas daninhas aos herbicidas, é necessário maior número de pesquisas para se compreender melhor a adaptabilidade ecológica dos biótipos. Portanto, são necessários, principalmente, estudos con- 
duzidos em condições ecológicas naturais, particularmente em condições de campo (Holt, 1990), tais como a pesquisa desenvolvida por Christoffoleti (1992).

\section{BANCOS DE SEMENTES NO SOLO}

O banco de sementes pode retardar o aparecimento de biótipos de plantas daninhas resistentes a um determinado herbicida. Quanto maior for o período de dormência das sementes das plantas daninhas, maior será o tempo necessário para esgotar o banco de sementes do biótipo suscetível no solo, mesmo que haja pressão de seleção muito forte. A rapidez no desenvolvimento da resistência de plantas daninhas aos herbicidas depende muito da persistência das sementes no solo, características de germinação da espécie daninha e sistema de cultivo usado anteriormente ao estabelecimento da cultura (Gressel \& Segel, 1990).

\section{MODELOS MATEMÁTICOS}

Diversas tentativas têm sido feitas no sentido de desenvolver modelos matemáticos que integrem processos genéticos, fisiológicos e ecológicos envolvidos na evolução de populações de plantas daninhas resistentes aos herbicidas (Gressel \& Segel, 1990). Esses modelos enfatizam a importância relativa dos fatores que afetam o desenvolvimento e disseminação de resistência, mencionados na seção anterior. Os modelos, em geral, referem-se à resistência herdada por um ou poucos genes principais, por exemplo, resistência às triazinas, inibidores da enzima AIS, paraquat e dinitroanilinas, o qual parece ser monogenicamente herdada na maioria dos casos estudados até agora. Contudo, a maioria dos princípios incorporados nos modelos também deve ser relevante à resistência herdada poligenicamente.

O modelo de Gressel \& Segel (1990) estima o aumento na proporção de plantas resistentes e o relaciona com o tempo em uma população baseada nos seguintes aspectos: a. frequiência inicial de um genótipo resistente; b. pressão de seleção imposta pelo herbicida; c. adaptação ecológica relativa do biótipo resistente comparada à do suscetível na ausência de herbicidas e, d. longevidade do banco de sementes no solo. O modelo de Maxwell et al. (1990) enfatiza a importância de processos principais que determinam a dinâmica da resistência de plantas daninhas aos herbicidas. Dentre os principais processos, primeiramente são destacados a sobrevivência e a fecundidade, ambas influenciadas pela competição entre plantas e que afetam a adaptação de biótipos resistentes relativamente ao biótipo susceptível. E, secundariamente, processos que contribuem para o fluxo de genes no espaço e no tempo e alteram a freqüência de alelos resistentes e susceptíveis em uma população, tais como a imigração de pólen e sementes, dormência de sementes e tipo de sistema de seleção.

Apesar da diferença entre os dois modelos ao enfatizar a importância relativa dos processos biológicos específicos, as previsões dos dois são similares. Ambos os modelos concluem que a pressão de seleção deve ser reduzida para prevenir o desenvolvimento da resistência. No entanto, os dois modelos diferem nas estratégias propostas para alcançar os objetivos finais.

\section{MECANISMOS DE RESISTÊNCIA}

A resistência de plantas daninhas aos herbicidas pode resultar de mudanças bioquímicas e fisiológicas, alterações morfológicas ou mudanças fenológicas de certos biótipos de plantas daninhas. Muitos casos de resistência aos herbicidas resultam tanto de alteração do sítio de ação do herbicida ou aumento do seu metabolismo, quanto da departamentalização e compartimentalização do herbicida na planta. São poucos os relatos de mudanças fisiológicas ou morfológicas. Apesar desses mecanismos gerais serem similares a alguns mecanismos de seletividade das culturas, os quais permitem que elas sobrevivam à exposição aos herbicidas, os mecanismos específicos de resistência aos herbicidas em plantas daninhas normalmente diferem substancialmente daqueles responsáveis pela seletividade das culturas (Lebaron \& McFarland, 1990), conforme as discussão a seguir.

\section{SÍTIOS DE AÇÃO ALTERADOS}

Os mecanismos responsáveis pela maioria dos casos de resistência às triazinas, inibidores da enzima ALS e dini troanilinas envolvem modificações nos sítios de ação dos herbicidas. Os herbicidas do grupo das triazinas possuem como modo de ação a inibição fotossintética. Na maioria das plantas daninhas a resistência é devida a mutações que alteram o sítio de ação da triazina na membrana tilacóide no cloroplasto (Fuert \& Horman, 1991). A resistência à triazina é absoluta, de tal forma que plantas daninhas resistentes suportam muitas vezes (freqüentemente acima de 100 vezes) a dose do herbicida normalmente recomendada para o seu controle. As plantas daninhas resistentes às triazinas exibem graus variáveis de resistência cruzada a outros herbicidas que inibem o fotossistema II, como as triazinonas, uracilas e uréias substituídas. Apesar de esses herbicidas agirem sobre o mesmo ponto dentro do fotossistema II, cada um tem uma orientação específica no sítio de ação, o que, provavelmente, explica as diferenças observadas nos padrões de resistência cruzada (Trebst, 1991). A resistência das plantas daninhas às triazinas não é herdada pelo genoma nuclear, mas pela herança maternal do DNA citoplasmático existente dentro do cloroplasto (Souza Machado, 1982). Conseqüentemente, a resistência às triazinas não é transmitida via pólen. Dessa forma, toda progênie de uma planta resistente será também resistente.

Resistência aos herbicidas inibidores da enzima ALS, como ao clorosulfuron, é devida a uma alteração do gene responsável pela codificação desta enzima, que cataliza o primeiro passo da biossíntese dos aminoácidos leucina, isoleucina e valina (Shaner, 1991). Essa enzima é o alvo de inibição dos herbicidas pertencentes aos diversos grupos químicos, incluindo as sulfoniluréias (LaRosa \& Schloss, 1984; Ray, 1984), imidazolinonas (Hawkes, 1989) e triazolopi rimidinas sulfoanilidas (Gerwilk et al., 1990; Subramaniam et al., 1990). Porém, existem posições múltiplas onde a enzima ALS pode sofrer mutações para conferir 
resistência. Essas mutações em diferentes locais são, provavelmente, responsáveis pelos graus variáveis de insensibilidade a diferentes sulfoniluréias e a diferentes padrões de resistência cruzada aos herbicidas do grupo das imidazolinonas.

Um sítio de ação alterado foi também encontrado em um biótipo de Eleusine indica altamente resistente aos herbicidas pertencentes ao grupo das dinitroanilinas. As dinitroanilinas interferem com a divisão celular, mas em plantas resistentes já foi demonstra do que a proteína tubulina, a maior constituinte do microtúbulo, é insensível ao herbicida (Vaughn \& Vaughn, 1990). Os mecanismos de resistência de outras plantas daninhas às dinitroanilinas como Setaria viridis no Canadá (Morrison et al., 1991) ainda não foram elucidados.

\section{METABOLISMO DIFERENCIAL}

Metabolismo diferencial é um importante mecanismo de seletividade das plantas daninhas diante dos herbicidas. Vários biótipos desenvolveram resistência aos herbicidas devido à capacidade de degradar rapidamente e/ou conjugar o herbicida com componentes menos tóxicos. Moss (1992) mostrou que Abutilon theophrasti é resistente à atrazina devido a uma maior destoxificação do herbicida via glutationa, como ocorre na planta de milho. Essa resistência metabólica aos herbicidas do grupo das triazinas tem sido relatada menos frequientemente do que a forma de resistência dos sítios de ação alterados, descritas na seção anterior.

Algumas populações de Alopecurus myosuroides no Reino Unido desenvolveram resistência a um amplo espectro de herbicidas com diferentes mecanismos de ação (Moss, 1992). Esses incluem clorotoluron (uma uréia substituída que inibe a fotossíntese), diclofop-metil (um inibidor da enzima ACCase) e pendimetalin (uma dinitroanilina que interfere na divisão celular). Resistência ao clorotoluron, pelo menos em algumas populações de plantas daninhas, parece ocorrer pela degradação rápida do herbicida via processos oxidativos de desalquilação do $\mathrm{N}$ e de oxidação do anel alquil associado com o citocromo Poso (Kemp et al., 1990). Resistência cruzada com outros herbicidas pode ser o resultado de destoxificação por processos oxidativos similares. O fator crítico parece ser o grau nos quais os herbicidas podem ser metabolizados e então destoxificados. Isso depende da estrutura molecular, mas não está relacionado com a classificação convencional dos herbicidas. O possível envolvime nto de monoxigenases do citocromo Poso em várias reações oxidativas, levando à destoxificação de vários herbicidas em plantas, foi revisto recentemente por Jones (1991).

Na Austrália, algumas populações de Lolium rigidum resistentes ao diclofop-metil mostraram também resistência cruzada a um largo espectro de outros herbicidas, incluindo o clorosulfuron do grupo das sulfoniluréias. Há evidências de que a resistência ao clorosulfuron, pelo menos em algumas populações de plantas daninhas, seja devida ao aumento do metabolismo em plantas resistentes (Christopher et al., 1991). Contudo, as diferenças nas taxas de metabolis mo entre biótipos são insuficientes para explicar as diferenças substanciais na resposta ao diclofop-metil, ao nível da planta toda. Por isso, outros mecanismos de resistência têm sido propostos (Holtum et al., 1991).

\section{DEPARTAMENTALIZAÇÃO OU COMPARTIMENTALIZAÇÃO}

Vários estudos indicam que a compartimentalização pode ser responsável, pelo menos parcialmente, por alguns casos de resistência aos herbicidas. A compartimentalização pode ser alcançada pelo armazenamento desses herbicidas ou de seus metabólitos tóxicos no vacúolo das células ou tecidos localizados distantes dos sítios de ação do herbicida (Compland, 1991). Este tipo de mecanismo tem sido sugerido como um dos mais importantes na resistência de plantas daninhas ao herbicida paraquat, excluindo-o assim do sítio de ação no clomplasto. Embora, para este herbicida, especific ações alternativas tenh am sido também suge ridas, tal como a rápida destoxificação enzimática (Dodge, 1991).

\section{PREVENÇÃO E CONTROLE DA RESISTÊNCIA}

$\mathrm{Na}$ maioria das vezes, a resistência de biótipos de plantas daninhas aos herbicidas ocorre como conseqüência do uso repetido do mesmo herbicida ou de herbicidas com o mesmo mecanismo de ação, sempre associado a monoculturas. E necessário, portanto, modificar essas práticas de modo a prevenir ou retardar o estabelecimento da resistência em alguns biótipos de plantas daninhas. Dentre algumas destas práticas mais recomendadas podem-se descrever:

\section{HERBICIDAS ALTERNATIVOS}

O uso de herbicidas alternativos ainda eficientes em populações de plantas daninhas resistentes, pode ser uma estratégia de sucesso, pelo menos a curto prazo. Em algumas situações, plantas resistentes são mais facilmente controladas por herbicidas alternativos que as plantas susceptíveis (Gressel \& Seguei, 1990). Isso é normalmente denominado resistência cruzada negativa. Contudo, se usado repetidamente, há um alto risco de se desenvolver resistência ao herbicida alternativo.

\section{MISTURAS OU SEQÜÊNCIAS DE HERBICIDAS}

O uso de dois ou mais herbicidas, com diferentes mecanismos de ação, deveria reduzir a pressão de seleção do genótipo resistente. $\mathrm{O}$ valor de tal estratégia depende da eficácia relativa de cada um dos herbicidas na planta daninha alvo e a especificidade dos mecanismos de resistência.

\section{MANEJO DE HERBICIDAS}

A pressão de seleção é reduzida se forem usados herbicidas sem nenhuma ou com pouca atividade residual no solo. Igualmente, as reduções de doses de herbicida e do número de aplicações por ano agrícola reduzem os riscos de desenvolvimento de resistência de plantas daninhas aos herbici das. $\mathrm{O}$ uso do mesmo herbicida apenas a cada 2 a 3 anos pode 
ser uma alternativa viável para reduzir a probabilidade do aparecimento de plantas daninhas resistentes a estes herbicidas.

\section{NÍVEL DE DANO ECONÔMICO}

A otimização de doses e número de aplicações de herbicidas, de tal forma que a intensidade de controle das plantas daninhas seja feita até se atingir o nível de dano econômico, reduz o uso desnecessário de herbicidas. Esta medida de otimização reduz a pressão de seleção imposta pelo herbicida. Além disso, permite a sobrevivência de plantas susceptíveis, proporcionando maior polinização cruzada entre indivíduos resistentes e susceptíveis em espécies alógamas, o que pode reverter o processo de seleção.

\section{ROTAÇÃO DE CULTURAS}

Muitas espécies daninhas estão em sincronia com culturas específicas. Assim, a rotação de culturas pode reduzir o sucesso intrínseco dessas plantas e, em muitas situações, permitir o uso de herbicidas alternativos.

\section{SISTEMAS DE CULTIVO}

Sistemas de cultivo mínimo são amplamente utilizados por razões de conservação de solo e água. O cultivo mínimo, contudo, favorece alguns tipos de plantas daninhas, especialmente algumas anuais e perenes. Sendo assim, requer maior uso de herbicidas. O cultivo mínimo ou plantio direto facilita o desenvolvimento da população de plantas daninhas proveniente de sementes produzidas na cultura anterior, pois as sementes são mantidas na superfície do solo. Neste tipo de cultivo existe uma minimização da probabilidade de retrocruzamentos com gerações anteriores não selecionadas, provenientes de sementes mais velhas enterradas a maiores profundidades. Aração com inversão das leivas utilizada no cultivo tradicional pode reduzir a necessidade de herbicidas e assim reduzir a pressão de seleção. Em algumas situações, a aração feita anualmente não é recomendável, mas aração rotacional, urna vez a cada 4 a 5 anos, pode ser uma alternativa viável, pois com isso muda a flora de plantas daninhas existentes através de uma maior diversificação (Cussan \& Moss, 1982). Cultivo nas entrelinhas e uso de herbicida apenas na linha da cultura pode ser um método bastante interessante para evitar o aparecimento de resistência em uma área, pois proporciona uma menor pressão de seleção. A praticidade e eficiência destas medidas dependem da cultura bem como das condições edificas e climáticas.

\section{OUTRAS TÉCNICAS CULTURAIS}

Outras técnicas de controle das plantas daninhas sem o uso de herbicidas foram revistas por Morgan (1989). Técnicas, como culturas mais competitivas, espaçamentos mais adensados, controle biológico e uso de cobertura morta são métodos não-químicos de controle de daninhas que podem ser, em algumas situações, alternativas viáveis juntamente com os herbicidas.
Como se pode observar, todas as recomendações para prevenção e controle da resistência de plantas daninhas aos herbicidas são baseadas em alternativas que auxiliem o controle químico das mesmas. Sendo assim, fica bastante claro que o método integrado de controle das plantas daninhas é a alternativa mais viável para a agricultura moderna. Os herbicidas constituem-se hoje no principal método de controle das plantas daninhas. No entanto, não se deve esquecer que a integração com outros métodos possibilita que tais espécies não evoluam de tal maneira a tornarem-se resistentes ao método químico de controle. Aliás, a boa prática agrícola sempre recomendou o controle integrado de plantas daninhas por diversas razões bem conhecidas. Dessa maneira, a resistência destas plantas a um método de controle usado repetidamente representa mais uma razão para a utilização do controle integrado. E importante também ressaltar que as plantas daninhas podem desenvolver resistência não apenas ao controle químico, mas a qualquer método de controle, desde que este seja usado de maneira intensa, impondo uma pressão de seleção forte sobre tais espécies.

\section{CONCLUSÕES}

A resistência de plantas daninhas aos herbicidas tem ocorrido em diversos países. A razão provavelmente seja a utilização repetida de uni mesmo produto para controlar plantas daninhas em certas áreas. Esta resistência se constitui num problema disseminado, principalmente em áreas onde os herbicidas são usados intensivamente, como único método de controle. No Brasil não existem relatos da ocorrência de resistência de plantas daninhas a herbicidas. No entanto, é extremamente importante observar relatos de outros países para alertar quanto aos possíveis problemas que poderão ocorrer, ou, quem sabe, já estão ocorrendo. Os fatores que proporcionam o aparecimento da resistência de plantas daninhas aos herbicidas não são totalmente conhecidos. Essa falta de conhecimento limita previsões e recomendações específicas para o controle da resistência em áreas agrícolas.

Diversos trabalhos de pesquisas têm sido conduzidos com o objetivo de se entender as bases fisiológicas e bioquímicas da resistência de certos biótipos de plantas daninhas aos herbicidas. No entanto, a ciência das plantas daninhas está muito longe de entender completamente os processos de resistência. Sendo assim, novas pesquisas precisam ser desenvolvidas. Está claro que a mesma espécie daninha pode desenvolver resistência a vários herbicidas de formas diversas, bem como a resistência ao mesmo herbicida pode estar baseada em diferentes mecanismos nas espécies de plantas daninhas. E também possível que vários mecanismos de resistência possam ser desenvolvidos em uma mesma espécie. Por exemplo, tem muita ênfase dado a um único mecanismo de resistência para explicar cada caso. No entanto, a população de plantas daninhas é bastante polimórfica, e, conseqüentemente, elas podem sobreviver porque possuem mais de um mecanismo de resistência. Obviamente, é necessário compreeder melhor a complexa interação entre mecanismos de ação dos herbicidas, ecologia das plantas dani nhas, genética e mecanismos da resistência. 
Não há uma estratégia geral para combater o desenvolvimento da resistência aos herbicidas, de tal forma que ela seja apropriada em todas as circunstâncias. Contudo, está claro que se faz necessário uma aproximação mais ampla, na qual o uso do herbicida seja integrado com métodos nãoquímicos de controle das plantas daninhas.

\section{LITERATURA CITADA}

BANDEEN, J.D.; STEPHENSON, G.R.; COWETI, E.R. Discovery and distribution of herbicide-resistant weeds in North America. In: LeBARON, H.M. e GRESSEL, J. Herbicide resistance in plants. New York: John Willey, 1982. p.9-30.

CHAUVAL, B.; GASQUEZ, J. Study of the growth of herbicide-resistant black-grass populations. In: CASELEY, J.C.; CUSSANS, G.W.; ATKINS, R.K. Herbicide resistance in weeds and crops. Oxford: Butterworth- Heinemann, 1991. p.431-432.

CHRISTOFFOLETI, P.J. Growth, competitive ability, and fitness of sulfonylurea resistant and susceptible Kochia scoparia biotypes. Fort Collins: Colorado State University, 1992. 198 p.Tese de Doutorado.

CHRISTOPHER, J.T.; POWLES, S.B.; LILJEGREN, D.R.; HOLTUM, J.A.M. Cross-resistance to herbicides in annual ryegrass (Lolium rigidum). II. Chlorsulfuron resistance involves a wheat-like detoxification system. Plant Physiology, v.95, p.1036-1043, 1991.

CLAY, D.V. New development in triazine and paraquat resistance and co-resistance in weed species in England. In: Brighton Crop Protection Conference - Weeds. Proceedings. Brighton, 1989. p.317-324.

COMPLAND, D. The role of compartmentation of herbicides and theír metabolites in resistance mechanisms. In: CASELEY, J.C.; CUSSANS, G.W.; ATKIN, R.K. Herbicide resistance in weeds and crops. Oxford: Butterworth-Heinemann, 1991. p.263-278.

CUSSAN, G.W.; MOSS, S.R. Population dynamics of annual grass weeds. In: British Crop Protection Symposium: Decision Making in the Practice of Crop Protection. Proceedings. Croydon: British Crop Protection Council, 1982. p.91-98.

DODGE, A.D. Mechanisms of paraquat tolerance. In: CASELEY, J.C.; CUSSANS, G.W.; ATKIN, R.K. Herbicide resistance in weeds and crops. Oxford: Butterworth-Heinemann, 1991. p.165-175.

FUERT, E.P.; HORMAN, M.A. Interactions of herbicides with photosynthetic electron transport. Weed Science, v.39, p.458-464, 1991.

GERWILK, B.C.; SUBRAMANIAN, M.A.; GALLANT, U.I.; CHANDLER, D.P. Mechanism of action of the 1,2,4-triazolo-1.5-a-pyrimidines. Pest. Sci., v.29, p.357-364, 1990.
GRESSEL, J. Why get resistance? It can be prevented or delayed. In: CASELEY, J.C.; CUSSANS, G.W.; ATKIN, R.K. Herbicide resistance in weeds and crops. Oxford: Butterworth-Heinemann, 1991. p.1-25.

GRESSEL, J.; SEGEL, L.A. Herbicide rotations and mixtures: effective strategies to delay resistance. In: GREEN, M.B.; LeBARON, H.L.; MOBERG, W.K. Managing resistance to agrochemicals: from fudamental research to practical strategies. Washington: American Chemical Society, 1990. p.430458.

HAWKES, T.R. Studies of he rbicides which inhibit branched chain amino acid biosynthesis. In: COPPING, L.G.; DALZIEL, J.; DODGE, A.D. Prospects for amino acids biosynthesis inhibitors in crop protection and pharmaceutical chemistry. Great Britain: Society of Chemical Industry Survey, 1989. p.131-138. (BCPC Monography, 42).

HOLT, J. Fitness and ecological adaptability of herbicide resistant biotypes. In: GREEN, M.B.; LeBARON, H.L.; MOBERG, W.K. Managing resistance to agrochemicals: from fudamental research to practical strategies. Washington: American Chemical Society, 1990. p.419-429.

HOLT, J.; LeBARON, H.M. Significance and distribution of herbicide resistance. Weed Technology, v.4, p.141$149,1990$.

HOLTUM, J.A.M.; MATTHEWS, J.M.; HAUSLER, J.M.; LILIEGREN, R.E.; POWLES, S.B. Cross-resistance to herbicides in annual ryegrass (Lolium rigidum). III. On the mechanisms of resistance to diclofop-methyl. Plant Physiology, v.97, p.1026-1034, 1991.

JONES, O.T.G. Cytochrome $\mathrm{P}_{450}$ and herbicide resistance. In: CASELEY, J.C.; CUSSANS, G.W.; ATKIN, R.K. Herbicide resistance in weeds and crops. Oxford: Butterworth-Heinemann, 1991. p.213-226.

KEMP, M.S.; MOSSET, S.R.; THOMAS, T.T. Herbicide resistance in Alopecurus myosuroides. In: GREEN, M.B.; LeBARON, H.L.; MOBERG, W.K. Managing resistance to agrochemicals: from fudamental research to practical strategies. Washington: American Chemical Society, 1990. p 376393.

LaROSA, R.A.; SCHLOSS, J.V. The sulfonilurea herbicide sulfometuron methyl is an extremelly potent and selec tive inhibitor of acetolactate synthase in Salmonella typh imurium. J. Biol. Chem. v.259, p.8753-8757, 1984.

LeBARON, H.M. Distribution and seriousness of herbicide resistant weed infestations worldwide. In: CASELEY, J.C.; CUSSANS, G.W.; ATKIN, R.K. Herbicide resistance in weeds and crops. Oxford: ButterworthHeinemann, 1991. p.27-43.

LeBARON, H.M. Herbicide resistance in crops and weeds and its management. In: TROPICAL WEED SCIENCE CONFERENCE, 3., 1992, Kuala Lumpur. Proceedings. Kuala Lumpur, 1992. p.23-24. 
LeBARON, H.M; McFARLAND, J. Herbicide resistance in weeds and crops: an overview and prognosis. In: GREEN, M.B.; LeBARON, H.L.; MOBERG, W.K. Managing resistance to agrochemicals: from fundamental research to practical strategies. Washington: American Chemical Society, 1990. pp 336-352.

LUTMAN, P.J.W. Variations in the resistance of Stellaria media to mecoprop due to biotype, application method and 1-aminobenzotriazole. Weed Research, v.30, p.129-137, 1990.

MAXWEL, B.D.; ROUSH, M.L.; RADOSEVICH, S.R. Predicting the evolution and dynamics of herbicides resistance in weed populations. Weed Technology, v.4, p.2-13, 1990.

MORGAN, W.C. Alternatives to herbicides. Plant Protection Quaterly, v.4, n.1, p.33-37, 1989.

MORRISON, I.N.; BECKIE, H.; NAWOLSHY, K. The occurence of trifluralin resistant Setaria viridis (green foxtail) in western Canada. In: CASELEY, J.C.; CUSSANS, G.W.; ATKIN, R.K. Herbicide resistance in weeds and crops. Oxford: Butterworth-Heinemann, 1991. p.67-75.

MOSS, S.R. Herbicide resistance in the weed Alopecurus myosuroides (black-grass): the current situation. In: DENHOLM, I. ; DE V ONSHIRE, A.L.; HOLOLOMAN, D.W. Achievements and developments in combating pesticide resistance. London: Elsevier Applied Science Pub., 1992. p.28-40.

RAY, T.B. Site of action of chlorsulfuron inhibition of valine, and isoleucine biosynthesis in plants. Plant Physiology, v.75, p.827-831, 1984.

RUBIM, B. Herbicide resistance in weeds and crops, progress and prospects. In: CASELEY, J.C.; CUSSANS, G.W.; ATKIN, R.K. Herbicide resistance in weeds and crops. Oxford: Butterworth-Heinemann, 1991. p.387-414.

RYAN, G.F. Resistance of common groundsel to simazine and atrazine. Weed Science, v.18, p.614-616, 1970.

SAWICKI, R.M. Definition, detection and documentation of insecticide resistance. In: FORD, M.G.; HOLLOMAN, D.W.; KHAMBAY, B.P.S.; SAWICKI, R.M. Combating resistance to xenobiotics: biological and chemical app roa ches. Chi che ster: Ell is Horwood, 1987. p.105-117.

SCHONFELD, M.; YAACOB Y, T.; MICHAEL, O. ; RUBIM, B. Triazine resistance without reduced vigour in Phalaris paradoxa. Plant Physiology, v.83, p.329333, 1987.
SHANER, D.L. Mechanisms of resistance to acetolactate synthase/acetohydroxyacid synthase inhibitors. In: CASELEY, J.C.; CUSSANS, G.W.; ATKIN, R.K. Herbicide resistance in weeds and crops. Oxford: Butterworth-Heinemann, 1991. p.187-198.

\section{SILVERTOWN, J.W. Int rod uction to plant population}

ecology. 2. ed. New York: Longman, 1987. 220 p.

SOUZA MACHADO, v.Inheritance and breeding potential to triazine tolerance and resistance in plants. In: LeB ARO N, H.M.; GRESSEL, J. Herbicide resis tance in plants. New York: John Wiley, 1982. p.257273.

ST ANNARD, M.E.; FAY, P. K. Selection of alfalfa seedlings for tolerance to chlorsulfuron. In: WEED SCIENCE SOCIETY OF AMERICA MEETING, 61. Proceedings. 1987. p.45.

SUBR AM ANIA M, M. V.; HUNG, H.Y.; DI AS, J.M.; MINES, U.W.; BUTLER, J.H.; JACHETA, J.J. Properties of mutant acetolactate synthase resistant to triazolopyrimidines sulfoanilide. Plant Physiology, v.94, p.239-244, 1990.

TRILL, D.C.; MALLORY-SMITH, C.A.; SAARI, C.A.; COTTERMAN, L.L.; PRIMIANI, M.M.; SALADINI, J.L. Sulfonylurea herbicide resistant weeds: discovery, distribution, biology, mechanisms, and management. In: CASELEY, J.C.; CUSSANS, G.W.; ATKIN, R.K. Herbicide resistance in weeds and crops. Oxford: Butterworth-Heinemann, 1991. p.115-128.

TREBST, A. The molecular basis of resistance of photosystem II herbicides. In: CASELEY, J.C.; CUSSANS, G.W.; ATKIN, R.K. Herbicide resistance in weed s and crops. Oxford: Butterworth-Heinemann, 1991. p.145-164.

Van OORSCHOT, J.L.P. Chloroplastic resistance of weeds to triazines in Europe. In: CASELEY, J.C.; CUSSANS, G.W.; ATKIN, R.K. Herbicide Resistance in weeds and crops. Oxford: Butterworth-Heinemann, 1991. p.87-101.

VAUGHN, K.C.; VAUGHN, M.A. Structural and biochemical characterization of dinitroanilines-resistant Eleusine. In: GREEN, M.B.; LeBARON, H.L.; MOBERG, W.K. Managing resistance to agro-chemicals: from fudamental research to practical strategies. Washington: American Chemical Society, 1990. p.364-375. 